\title{
An overview of current situations of robot industry development
}

\author{
Qiong $\mathrm{Wu}^{1, *}$ a , Yanjun Liu ${ }^{1, \mathrm{~b}}$, and Chensheng $\mathrm{Wu}^{1, \mathrm{c}}$ \\ ${ }^{1}$ No.140, Xizhimenwai Street, Xicheng District, Beijing, 100044 P R CHINA. \\ awwqqppdd@163.com, ${ }^{\mathrm{b}} 65415643 @ q q . c o m,{ }^{\mathrm{c} w u 1082 @ 163 . c o m}$
}

\begin{abstract}
As an industry of emerging technology, robot industry has become one of important signs to evaluate a country's level in science and technology innovation and high-end manufacturing, and an important strategic field to take the preemptive opportunities in development of intelligent society. Developed countries such as the USA, Germany, France and Japan have formulated their robot R\&D strategies and planning in succession. China boasts good industrial foundation and has made encouraging progress in the course of development of robot technology. This paper briefly discusses the application type of robot industry and current situations of robot industry development in countries around the world, and makes detailed explanation of current situations of robot industry development in China.
\end{abstract}

\section{Introduction}

Robot is a kind of automation equipment combining advanced technologies of multiple disciplines such as machinery, electronics, control, computer, sensor and artificial intelligence [1]. It is an automation technology and can execute some tasks under unmanned situation by programming. That is to say, robot can receive operator's instruction and then execute the instruction independently. In addition, robot is one of the forms of artificial intelligence (AI). HubSpot's market analyst Mimi An describes it as the "technology able to do things as human being can - regardless of conversation, vision and learning, or social contact and inference", just as AI applications in iPhone-based Siri and Google Assistant. Therefore, robot industry, as an industry of emerging technology, has become one of important signs to evaluate a country's level in science and technology innovation and high-end manufacturing, and an important strategic field to take the preemptive opportunities in development of intelligent society. Developed countries and regions such as the USA, Japan, the UK and the European Union have formulated their robot R\&D strategies and planning in succession. China boasts good industrial foundation and has made encouraging progress in the course of development of robot technology.

\footnotetext{
* Corresponding author: wwqqppdd@163.com
} 


\section{Current situations of robot industry development}

\subsection{Development history of robot}

\subsubsection{Infancy stage (1910-1960)}

First, the word of "Robot" was created by Karel Capek, a writer of Czechoslovakia, in 1910. In his science fiction, he first used the word "Robot" on the basis of Robota for "Hard Labor and Manual Work" and Robotnik for "Worker". The New York World's Fair 1911 in the USA displayed the home robot Elektro made by Westinghouse Electric Corporation. Elektro was controlled by cable and could walk, speak 77 words and even have a cigarette, making people's dream for home robot more specific. In 1914, American George Devol manufactured the world's first programmable robot (namely the first real robot in the world) and registered the patent. Such mechanical hand was equipped with versatility and flexibility, so it could do different jobs according to different programs. In 1959, Devol and American inventor Joseph Engelberger jointly manufactured the first industrial robot. Later, they established the first robot manufacturing factory Unimation in the world. In memory of Engelberger's contributions to R\&D of and publicity to industrial robot, he was called the "Father of Robotics"[2].

\subsubsection{Mid-term development stage (1961-1989)}

In 1962, American AMF Company produced "VERSTRAN" (meaning "Universal Handling"), which was a commercialized industrial robot in real sense and exported to many countries in the world, thus setting off a race of robot research around the world. Since the mid-1960s, American Massachusetts Institute of Technology and Stanford University and the British University of Edinburgh had established robot labs in succession, and the USA started an upsurge of research of $2 \mathrm{G}$ robot with sensor and "Feeling", and set out for AI. In 1968, Stanford Institute announced its successful robot Shakey. With visual sensor, able to find and grab blocks according to operator's instruction, Shakey could be taken as the first intelligent robot in the world, but the computer controlling it was as large as a room. In 1969, Kato Ichiro Lab of Waseda University, Japan researched and developed the first robot walking on two feet, for which Kato Ichiro was reputed as the "Father of Manlike Robot". In 1973, robot was firstly combined with minicomputer, promoting birth of Robot T3 by American Cincinnati Milacron Company. In 1978, American Unimation Company offered general-purpose industrial robot PUMA, marking that industrial robot technology had become mature completely. Today, PUMA is still serving production lines in factories. In 1984, Eagleburger further marketed Robot Helpmate able to deliver food, medicine and mails to patients in hospitals.

\subsubsection{Rapid development stage (since 1990)}

In 1998, Denmark Lego presented robot (Mind-storms) kits, making robot manufacturing as easy as building block, relatively simple and able to be realized through free piece-up assembly. Since then, robot began to enter individual world. In 1999, Japanese Sony marketed its dog-like robot AIBO, which was sold out at once. After that, entertainment robot became one of the ways for robot to enter common families. In 2002, American iRobot Company presented dust-extractor robot Roomba, which can avoid obstacles, automatically design advancement route and automatically drive to the charger if the power is insufficient. Roomba is the home robot with the highest sales and most commercialized in the world at present. In June 2006, Microsoft marketed Microsoft Robotics Studio, 
making robot more and more modular and uniform platform-based. Bill Gates predicted that home robot will sweep over the world very soon.

\subsection{Classification of robot applications}

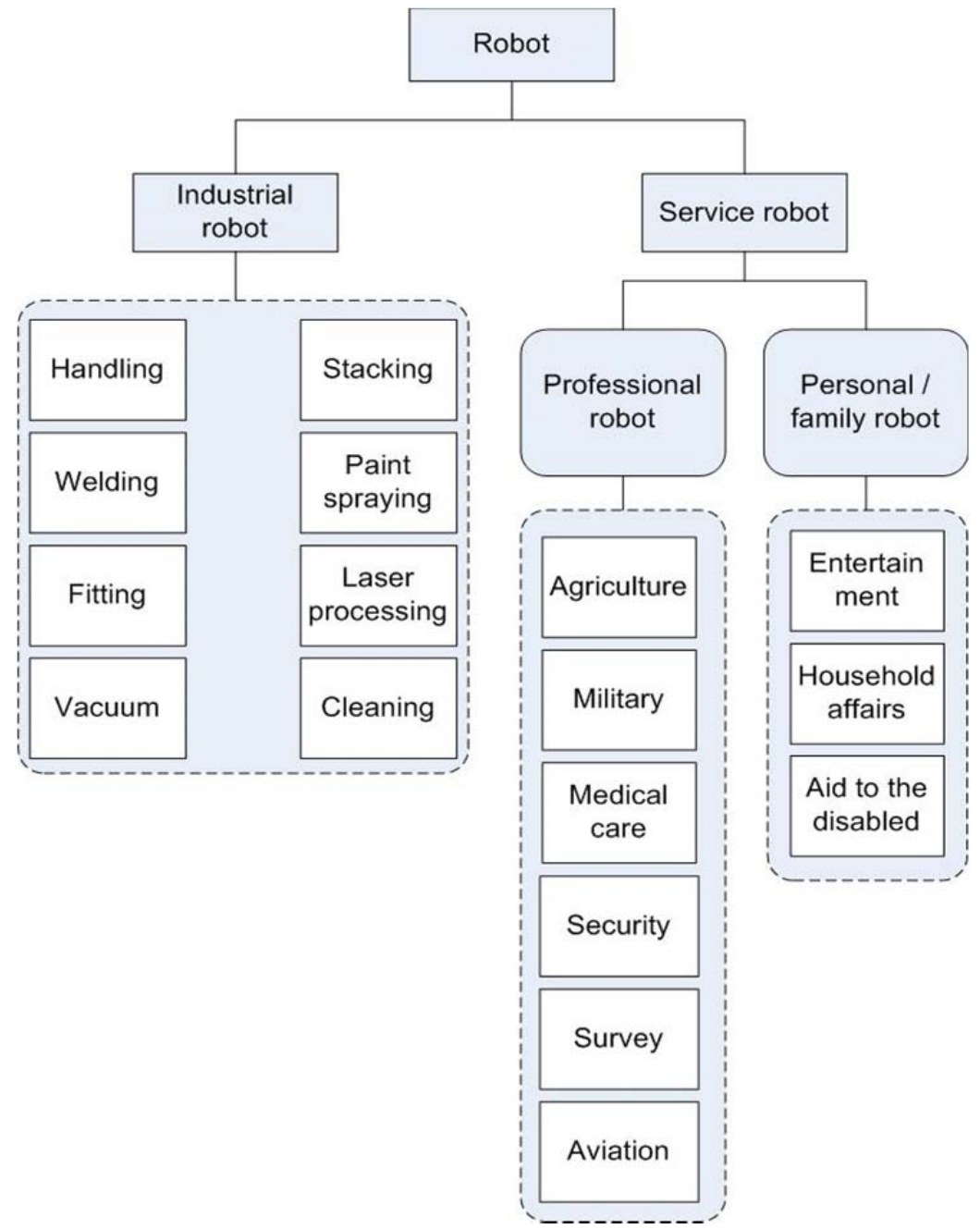

Fig. 1. Classification of Robot Applications

In terms of application fields, robot can be classified into industrial robot and service robot. The industrial robot means the multi-joint mechanical hand or multi-degree-of-freedom robot for industrial field, with typical applications including welding, handling, assembly, fitting, vacuum, spraying, stacking, laser processing and cleaning. The service robot consists of semi-automatic or fully automatic robot except for those in industrial production, including professional robot and family personal robot, of which, the professional robot includes exclusive robot for agriculture, military, medical care, security, survey and aviation (also called special robot) and the home robot for household affairs, entertainment and aid to the disabled[3]. 


\subsection{Current situations of robot industry development in countries around the world}

Currently, at least one third of countries in the world are in R\&D of robot. In the field of service robot, leading Western countries are represented by the USA, Germany and France and leading Asian countries are represented by Japan and ROK. Each of the countries has its own specialty in robot R\&D field and application type. For example, the USA focuses more on R\&D of military robot, while some EU countries have launched the biggest civilian robot $R \& D$ project in the world.

The USA is the birthplace of robot, and its robot technology keeps leading in the world, is complete, all-round, advanced and highly adaptable, and dominates in military, medical care and home service robot industry, with the market share of about $60 \%$; Germany is leading in service robot application research around the world, and its robot housekeeper Care-O-Bot3 is equipped with sensor, 3D color camera, laser scanner and 3D stereo camera. In addition, Care-O-Bot 3 also boasts the abilities of sound control or gesture control, self-learning and understanding voice order and gesture order; the Government of France attached importance to robot technology from the beginning, greatly supports service robot research plan, and has established a complete science and technology system, with the key in robot application research particularly; Japan is a major power in robot production, R\&D and use, and has always taken robot as a strategic industry and made great efforts to support the industry from technology and funds, with the R\&D mainly centering on service robot. In recent years, demands for robot products in old people nursing market promote enterprises to race in $\mathrm{R} \& \mathrm{D}$ of mini home robot; ROK also takes service robot technology as 10 major "Engine" industries for its development in the future, considers service robot as a new economic growth point, and gives key supports to robot technology[4].

\section{Current situations of robot industry development in China}

China's service robot market began to take initial shape in 2005 or so. Compared with Japan, the USA and other developed countries, China started late and has a big gap in R\&D of service robot, but has witnessed rapid and violent development in recent years. Many traditional robot user enterprises have entered robot industry through independent R\&D, investment and M\&A one after another and comprehensively applied technologies such as AI to develop service robot, and some innovative leading enterprises have emerged. For example, DJI-Innovations, Siasun Robot \& Automation Co., Ltd. and Shanghai STEP Robotics Co., Ltd. as well as other enterprises in the field have won their market share.

\subsection{Industrial robot}

Since 2013, industrial robot technology has developed vary fast in China under promotion of national policy guarantee and technology development. New technology will promote further development of robot technology. Technologically, China is now at the period of rapid development. By 2025 or so, industrial robot technology will realize a great progress in China. The Chinese Government attaches very high importance to R\&D of key components in speed reducer, servo and controller, as the three key components account for over $70 \%$ of the cost of industrial robot. Previously such components were mainly relied on foreign technology, but now they are made in China gradually.

By 2016, China had reported nearly 50 industrial parks for industrial robot completed or in progress and about 800 influential robot companies. At present, local governments have also recognized importance of robot and taken active measures to develop robot-related industries, with representative Chinese industrial robot enterprises including: Siasun Robot 
\& Automation Co., Ltd., Harbin Boshi Automation Co., Ltd. and Nanjing Estun Automation Co., Ltd[5].

\subsection{Service robot}

Intelligent service robot has become an emerging growth point of robot industry in China. In recent years, development of AI technology has further fueled R\&D of service robot, and voice interaction, face identification, automatic positioning and navigation as well as other AI technologies have been further integrated with traditional products, and innovative products have been presented continuously, for example, intelligent sound box marketed by Linglong Tech and Alibaba in succession and intelligent interaction robot built by Xiaomi Robot. In terms of policy, China has mapped out relevant policies in succession, which serve as the strategic power for priority to development of service robot. With great supports of the policies, 25 robot industrial parks have been built in China, which are mainly in the Yangtze River Delta, the Pearl River Delta and Beijing-Tianjin-Hebei region. There are 1393 relevant enterprises in Jiangsu, Zhejiang and Shanghai as well as Anhui Province in the Yangtze River Delta region, 784 relevant enterprises in Bohai-Rim Beijing-Tianjin-Hebei region, Shandong and Liaoning, and 747 relevant enterprises in the Pearl River Delta area including Guangdong Province.

At present, in robot products with initial shape such as cleaning robot and educational and entertainment robot, a batch of enterprises with good combination of production, study and research have emerged. According to the information released by relevant departments, Top 5 service robot enterprises in China in 2016 are: Guangzhou Joinmax Digital Technology Co., Ltd., Shenyang Unecox Robot Co., Ltd., Shenyang Siasun Robot Automation Co., Ltd., Mirle Automation Technology (Shanghai) Co., Ltd. and Shanghai PartnerX Robotics Co., Ltd.[6].

\subsection{Special robot}

The Chinese Government attaches high importance to research and development of special robot technology, and supports the development through 863 Program, theme projects of key technologies for robot operating under special service environment and deep-sea key technology and equipment, promoting continuous progress of special robot technology. By far, China has conquered multiple core technologies including Ti-alloy manned cabin spherical shell manufacturing, high-depth buoyancy material preparation and deep-sea impeller, helping China make remarkable progress in domestic production of core deep-sea equipment. In addition, China is now leading globally in research and development of special UAV and underwater robot, and has initially developed series products of special UAV, underwater robot, search and rescue/explosive-removal robot in special robot field and advantages in some fields. For example, China Electronics Technology Group Corporation has researched and developed fixed-wing UAV intelligent swarming system and successfully completed 119-set fixed-wing UAV swarming flight test; CRRC Times Electric Co., Ltd. has developed the highest-tonnage deep-water trenching plough in the world, filling a gap of China in deep-sea robot equipment manufacturing field; the cable-controlled ROV "Discovery" and the autonomous underwater robot "Exploration" on the new-generation ocean comprehensive scientific research vessel "Science" have realized the first deep-sea shooting by intersection in the north of the South China Sea. 


\section{Conclusion}

With development of technology and the advent of "Manpower Substitution" times, robot industry is extending from manufacturing industry to service industry, and countries in the world have taken robot industry as their development strategy one after another. Service robot, as an emerging field of robot industry, highly integrates intelligence, sensing, network, cloud computing and other innovative technologies and is combined with new mode of mobile Internet, providing a new window for promoting smart life and fueling industrial transformation.

\section{References}

1 Shi, M. China's Robot Industry Faces Severe Challenge in Development[J].Science \& Technology Review. 2014(32):9.

$2 \mathrm{Li}, \mathrm{J}$. Et al. Greatly Develop Robot Industry to Promote Industrial Transformation and Upgrading in our Province [R]. Hangzhou: Zhejiang Province Economic and Information Commission.2013.

3 Robot Development Strategies of Countries in the World [EB/OL].[2014-12-08].

4 IFR.World Robotics 2014 Industrial Robots [EB/OL]. [2014-12-08].

5 Liu, S. Influences of Intelligent Robot on our Life[J].Market Weekly.Disquisition Edition, 2015(3):114-116.

6 Huang, Y. Et al. Current Situations of Intelligent Robot Application and the Development Trend[J]. International Academic Developments. 2009(4):38-39. 